\title{
CHALLENGING MULTIVESSEL PERCUTANEOUS CORONARY INTERVENTION SUPPORTED WITH IMPELLA 2.5 VENTRICULAR ASSIST DEVICE
}

\author{
Karolina Jasinska, Aleksandra Gasecka $\bigotimes^{0}$, Arkadiusz Pietrasik, Janusz Kochman
}

1st Chair and Department of Cardiology, Medical University of Warsaw, Poland

KEY WORDS: Impella, PCI, MCS

Disaster Emerg Med J 2021; 6(2): 90-93

\section{INTRODUCTION}

Dynamic development of interventional cardiology enables percutaneous treatment of patients with multivessel coronary artery disease at high risk of perioperative mortality.

Such high-risk procedures include interventions in patients with severe systolic left ventricular (LV) dysfunction, and patients in cardiogenic shock in the course of myocardial infarction. These groups of patients frequently require short-term mechanical circulatory support (MCS) when undergoing highrisk percutaneous coronary intervention (PCl) [1]. Impella is an axial flow blood pump which can be percutaneously introduced via a 14 French sheath. The right-side Impella device pumps blood from the inferior vena cava into pulmonary artery, providing up to $4 \mathrm{l} / \mathrm{min}$ of blood flow. By unloading the right ventricle, it reduces the central venous pressure, enabling the increased pulmonary venous return to the left heart chambers $[2,3]$. The left-side device pumps blood from the LV into the ascending aorta, providing cardiac output from $2.5 \mathrm{l} / \mathrm{min}$ up to $5.0 \mathrm{l} / \mathrm{min}$, depending on the size of the device. By unloading the LV and increasing cardiac output and coronary flow, left-sided Impella provides hemodynamic stability during $\mathrm{PCl}$ procedures. We present a case report of a patient with severe systolic LV dysfunction who presented with sustained ventricular tachycardia and underwent Impella-supported multivessel PCI.

\section{CASE PRESENTATION}

A 62-year-old man suffering from heart failure with reduced ejection fraction (HFrEF) was admitted to the cardiology department due to recurrent sVT. The patient had a history of acute ST-elevation myocardial infarction (STEMI) of the anterior wall, treated with systemic thrombolysis (2001), non-ST-elevation myocardial infarction (NSTEMI), with unsuccessful attempt of $\mathrm{PCl}$ of the circumflex artery $(C x ; 2008)$ and an episode of sustained ventricular tachycardia (sVT). Moreover, he received implantable cardioverter-defibrillator with resynchronization therapy function (CRT-D) in the primary prevention of sudden cardiac death (2008) due to HFrEF [NYHA class II, ejection fraction (EF) 37\%] and left bundle branch block (QRS $176 \mathrm{~ms}$ ). During the last months, several episodes of ventricular tachycardia occurred, which were ineffectively treated with anti-tachycardia pacing and shock therapy. On admission, the patient was hemodynamically stable, without symptoms and signs of overt heart failure. Electrocardiogram revealed sinus rhythm with heart rate 50/min and biventricular pacing (Fig. 1). Echocardiography showed enlarged LV and both atria, akinetic inferior and posterior wall, hypokinetic lateral wall with LVEF of $20 \%$, diastolic dysfunction grade II and mild mitral and tricuspid regurgitation. Coronary angiography revealed chronic total occlusion of the right coronary artery in the proximal segment with collateral filling from the left coronary artery and 
significant stenoses of the left main coronary artery (LMCA), left anterior descending artery (LAD) and CX (Fig. 2A, 2B, 2C), which was confirmed based on the fractional flow reserve measurement $(0.64$ for $L A D$ and 0.73 for $(x)$.
Considering the intermediate risk of mortality according to the EuroScore II (6.81\%) and the high anatomical complexity of the lesions (SYNTAX score 43) the Heart Team opted for surgical revascularization, which the patient refused. Regarding persistent

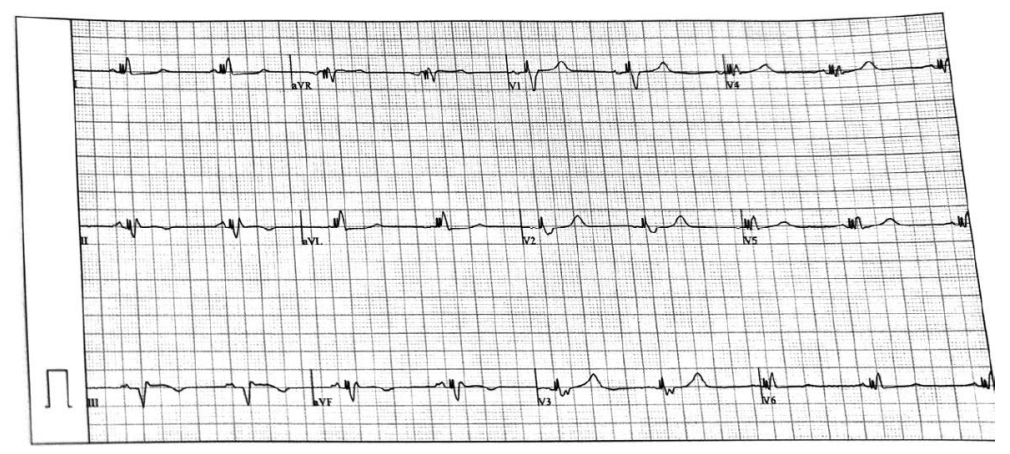

FIGURE 1. Electrocardiogram at admission. Sinus rhythm with heart rate $50 /$ min and biventricular pacing
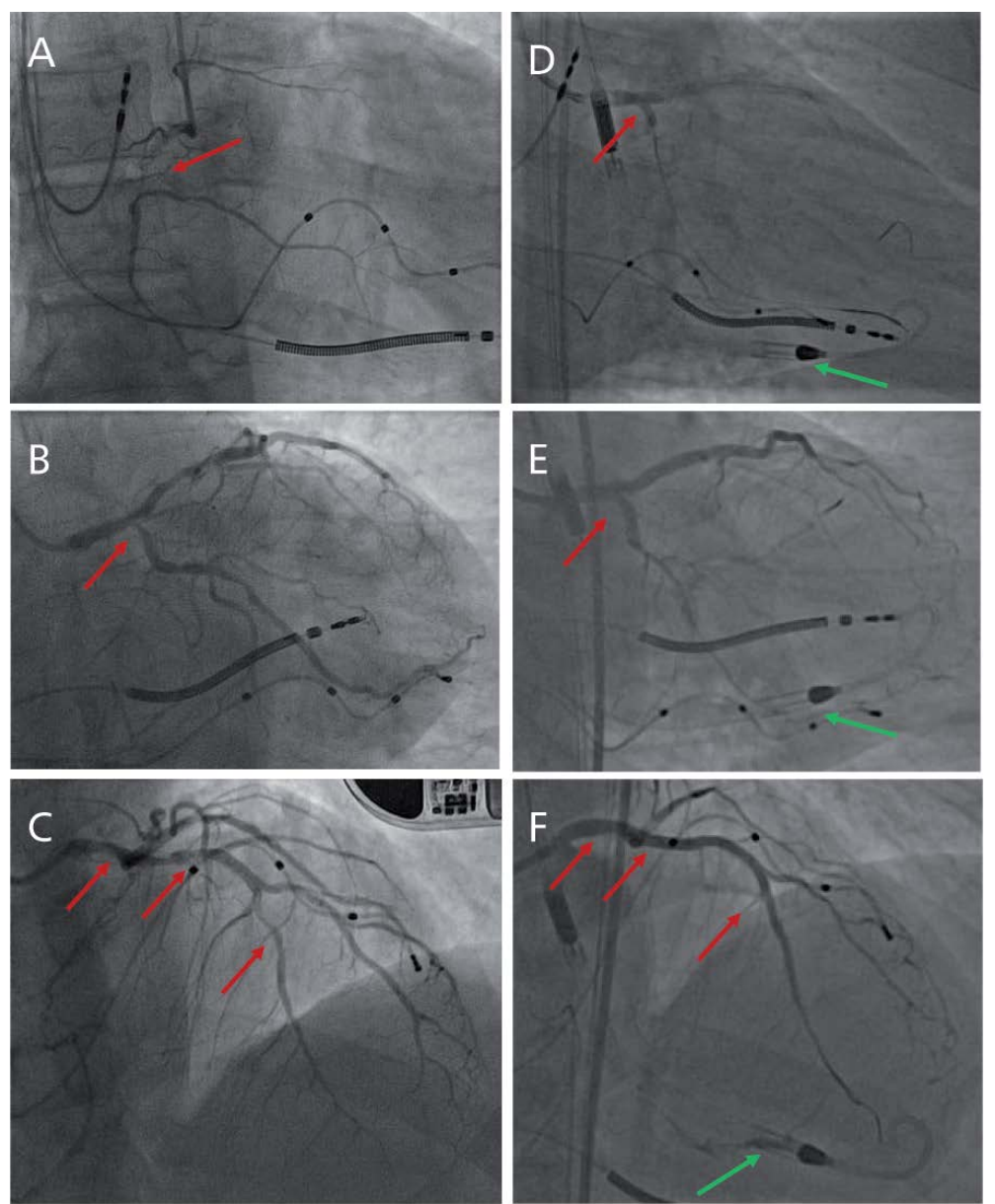

FIGURE 2. Coronary angiography. A: Chronic total occlusion of the right coronary artery in the proximal and middle segment (red arrow) with collateral filling from the left coronary artery. B: Significant stenosis of the circumflex artery $(\mathrm{Cx})$ ostium with FFR value 0.64 (red arrow). C: Significant stenoses of the left main coronary artery (LMCA) and left anterior descending artery (LAD) with FFR 0.73 (red arrows). D-F: Impella-assisted (green arrows) percutaneous coronary intervention with implantation of three overlapping everolimus-eluting stents were implanted to LMCA and LAD $(3.5 \times 38 \mathrm{~mm} ; 2.5 \times 38 \mathrm{~mm} ; 2.25 \times 23 \mathrm{~mm})$ and one stent to the ostium and proximal part of $C x$ $(2.75 \times 12 \mathrm{~mm})$ using DK crush technique. D: Final kissing with compliant balloons (3.5x12mm in the $\mathrm{Cx}, 4.0 \times 8 \mathrm{~mm}$ in the LAD; red arrows). E, F: Final result of the intervention (red arrows) 
ventricular arrhythmia, percutaneous treatment attempt was the only available alternative, for which the patient agreed.

An Impella 2.5 pump was inserted through the right femoral artery. Following predilation of the lesions in the proximal and mid LAD, two overlapping everolimus-eluting stents (EES) were implanted to $\operatorname{LAD}(2.5 \times 38 \mathrm{~mm} ; 2.25 \times 23 \mathrm{~mm})$ and the proximal part was postdilated with a compliant balloon $(3.0 \times 15 \mathrm{~mm}, 20 \mathrm{~atm}$.$) In the next step, the bifur-$ cation stenting of the LMCA was done using double-kissing (DK) crush technique, with the implantation of one EES to the ostium and proximal part of CX $(2.75 \times 12 \mathrm{~mm})$ and one EES to the LMCA towards $\operatorname{LAD}(3.5 \times 38 \mathrm{~mm})$. Final kissing was done with compliant balloons $(3.5 \times 12 \mathrm{~mm}$ in the $C x, 4.0 \times 8 \mathrm{~mm}$ in the LAD) obtaining proper expansion and coronary flow (Fig. 2D, 2E, 2F). Control angiography revealed perforation of the distal septal branch. Two vascular coils were successfully placed (Fig. 3A, 3B). Eventually, a satisfactory angiographic result of the procedure was achieved. The vascular access site was closed with ProGlide and AngioSeal devices.

Ten days after Impella-supported PCl, a successful ablation of recurrent VT was performed and patient was discharged on day 15. The pharmacotherapy at discharge included double antiplatelet therapy (acetylsalicylic acid and clopidogrel), proton-pump inhibitor, atorvastatin, beta-blocker (bisoprolol), angiotensin-converting enzyme inhibitor (ramipril), loop diuretic (torsemide), mineralocorticoid receptor antagonist (eplerenone). Control echocardiography showed LVEF of $26 \%$. During the 3-month follow-up, the patient was re-hospitalized for 10 days due to Coronavirus disease (COVID-19), from which he recovered. Further clinical course regarding adverse cardiovascular events was uneventful.

\section{DISCUSSION}

Patients in cardiogenic shock and those with severe systolic LV dysfunction and multivessel disease are a challenge of interventional cardiology. Traditionally, intra-aortic balloon pumps (IABP) were used to provide hemodynamic support during high-risk $\mathrm{PCl}$ in these clinical scenarios. However, the results of randomized clinical trials are inconsistent and have not confirmed the beneficial effect of IABP on long-term survival [4-6]. In contrast to IABP, which creates a reverse blood flow to coronary arteries during diastole, providing a non-physiological MCS, Impella facilitates blood flow during systole, offering a more effective, physiological support. Preliminary evidence from clinical trials demonstrated the advantage of Impella devices over IABP both in patients with cardiogenic shock and undergoing high-risk PCl [7-9]. However, there is a need to standardize the indications for the use of Impella in patients undergoing $\mathrm{PCl}[10,11]$ and to confirm the positive effect of Impella on the outcomes in large, randomized trials [12]. In the presented case, the use of Impella provided hemodynamic stability despite the low LVEF and multivessel disease enabling the effective performance of a high-risk PCl. The use of the pump did not prevent the recurrence of $\mathrm{CT}$. However, thanks to improved hemodynamic parameters, it was possible to perform ablation and improve patient's condition.
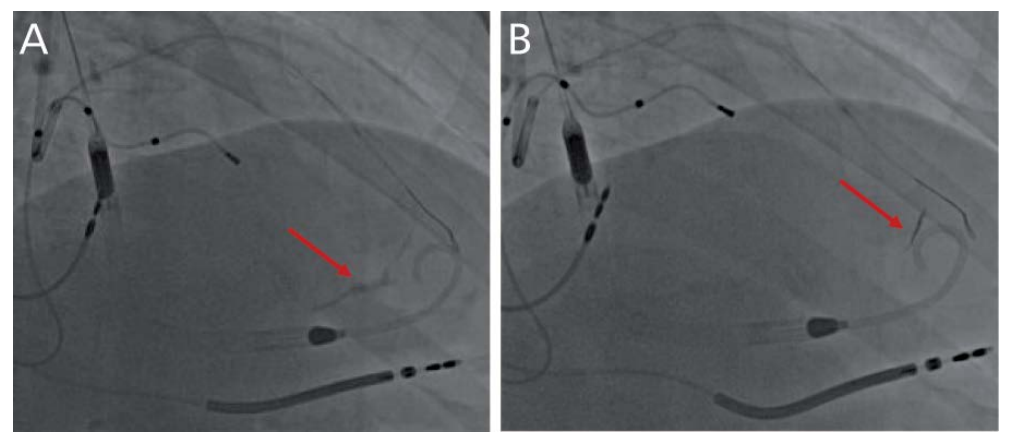

FIGURE 3. A: Perforation of the distal septal branch (most likely a fistula into the ventricle; red arrow). B: Perforation closure with two vascular coils (red arrow) 


\section{REFERENCES:}

1. Left Ventricular Assist Devices. SpringerReference. , doi: 10.1007/ springerreference_307916.

2. Burzotta F, Russo G, Previ L, et al. Impella: pumps overview and access site management. Minerva Cardioangiol. 2018; 66(5): 606-611, doi: 10.23736/S0026-4725.18.04703-5, indexed in Pubmed: 29687700.

3. Saxena A, Garan AR, Kapur NK, et al. Partial mechanical circulatory support in an ovine model of post-infarction remodeling. J Heart Lung Transplant. 2013; 32(8): 815-822, doi: 10.1016/j. healun.2013.05.019, indexed in Pubmed: 23856219.

4. Thiele H, Zeymer U, Neumann FJ, et al. IABP-SHOCK II Trial Investigators. Intraaortic balloon support for myocardial infarction with cardiogenic shock. N Engl J Med. 2012; 367(14): 1287-1296, doi: 10.1056/NEJMoa1208410, indexed in Pubmed: 22920912.

5. Bahekar A, Singh $M$, Singh $S$, et al. Cardiovascular outcomes using intra-aortic balloon pump in high-risk acute myocardial infarction with or without cardiogenic shock: a meta-analysis. J Cardiovasc Pharmacol Ther. 2012; 17(1): 44-56, doi: 10.1177/1074248410395019, indexed in Pubmed: 21335478.

6. Burzotta F, Russo G, Basile $E$, et al. [How to choose between intra-aortic balloon pump, Impella and extracorporeal membrane oxygenation]. G Ital Cardiol (Rome). 2018; 19(6 Suppl 1): 5S-513S, doi: 10.1714/2939.29545, indexed in Pubmed: 29989606.

7. O'Neill WW, Schreiber T, Wohns DHW, et al. The current use of Impella 2.5 in acute myocardial infarction complicated by cardiogenic shock: results from the USpella Registry. J Interv Cardiol. 2014; 27(1): 1-11, doi: 10.1111/joic.12080, indexed in Pubmed: 24329756.
8. Seyfarth $M$, Sibbing $D$, Bauer $I$, et al. A randomized clinical trial to evaluate the safety and efficacy of a percutaneous left ventricular assist device versus intra-aortic balloon pumping for treatment of cardiogenic shock caused by myocardial infarction. J Am Coll Cardiol. 2008; 52(19): 1584-1588, doi: 10.1016/j.jacc.2008.05.065, indexed in Pubmed: 19007597.

9. Dangas GD, Kini AS, Sharma SK, et al. Impact of hemodynamic support with Impella 2.5 versus intra-aortic balloon pump on prognostically important clinical outcomes in patients undergoing high-risk percutaneous coronary intervention (from the PROTECT II randomized trial). Am J Cardiol. 2014; 113(2): 222-228, doi: 10.1016/j.amjcard.2013.09.008, indexed in Pubmed: 24527505.

10. Amin AP, Spertus JA, Curtis JP, et al. The Evolving Landscape of Impella Use in the United States Among Patients Undergoing Percutaneous Coronary Intervention With Mechanical Circulatory Support. Circulation. 2020; 141(4): 273-284, doi: 10.1161/CIRCULATIONAHA.119.044007, indexed in Pubmed: 31735078.

11. Chieffo A, Ancona MB, Burzotta F, et al. Collaborators. Observational multicentre registry of patients treated with IMPella mechanical circulatory support device in ITaly: the IMP-IT registry. Eurolntervention. 2020; 15(15): e1343-e1350, doi: 10.4244/EIJ-D-19-00428, indexed in Pubmed: 31422925.

12. Alushi $B$, Douedari $A$, Froehlig $G$, et al. Impella versus IABP in acute myocardial infarction complicated by cardiogenic shock. Open Heart. 2019; 6(1): e000987, doi: 10.1136/openhrt-2018-000987, indexed in Pubmed: 31218000. 